\title{
Commentary: The behavior of leaders
}

Navyatha Mohan, MD, MPH, ${ }^{\mathrm{a}}$ and

Ikenna Okereke, MD ${ }^{\mathrm{b}}$

We read the article from Dr Pasque regarding surgical training with great interest. ${ }^{1}$ Dr Pasque has provided excellent advice for trainees regarding preparation, development of lifelong learning habits, handling uncomfortable learning opportunities, and being kind to staff and fellow trainees.

We disagree, however, with the thoughts expressed in the section titled "You Are a Lightning Rod." In the manuscript it says that "even the nicest CT surgeon" can become abusive while venting stress. Physical, emotional, and mental duress are part of our profession. How surgeons behave in moments of stress is a litmus test of character. Surgeons at all levels must be held to high standards of thoughtful and rational behavior under duress. Such behavior is indeed an integral part of what makes a great surgeon and leader.

We oppose the idea that trainees need to "suck it up and take the hit" when faced with abusive behavior. No trainee should consider abusive behavior to be a requirement of surgical education. In our current environment, trainees do not report most episodes of abusive behavior against them. ${ }^{2,3}$ The idea that abuse builds character and is necessary is a misconception that needs to be set aside. Trainees who are abused are incurring repetitive aggression that will in fact hinder their ability to learn. In addition, repetitive abuse of trainees has been shown to increase the risk of burnout, attrition, and suicidal ideation. ${ }^{4,5}$

\footnotetext{
From the a Division of Cardiothoracic Surgery, University of Texas Medical Branch, Galveston, Tex; and ${ }^{\mathrm{b}}$ Department of Surgery, Henry Ford Health System, Detroit, Mich.

Disclosures: The authors reported no conflicts of interest.

The Journal policy requires editors and reviewers to disclose conflicts of interest and to decline handling or reviewing manuscripts for which they may have a conflict of interest. The editors and reviewers of this article have no conflicts of interest.

Received for publication July 1, 2021; revisions received July 1, 2021; accepted for publication July 2, 2021; available ahead of print July 6, 2021.

Address for reprints: Ikenna Okereke, MD, Department of Surgery, Thoracic Surgery,

Henry Ford Health, 2799 E Grand Blvd, Detroit, MI 48202 (E-mail: ikokerek@ utmb.edu).

J Thorac Cardiovasc Surg 2022;164:e263-4

$0022-5223 / \$ 36.00$

Copyright (c) 2021 by The American Association for Thoracic Surgery

https://doi.org/10.1016/j.jtcvs.2021.07.003
}

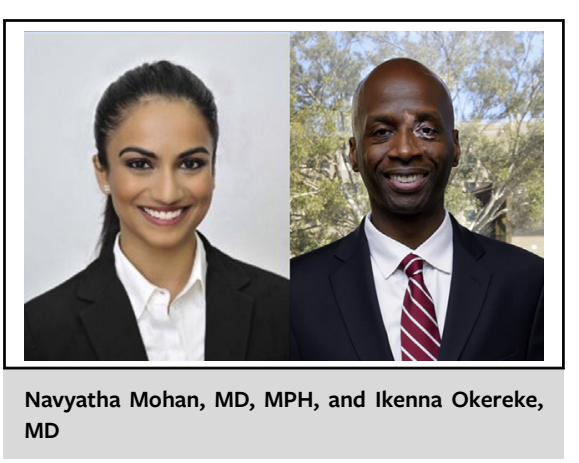

CENTRAL MESSAGE

The behavior and approach to learning that trainees adopt will influence their learning. Similarly, the behavior of their attendings will affect the learning environment.

We also disagree that derogatory attacks are not personal, and that silence is the best response. Minorities and female trainees tend to be bullied more frequently, indicating that there is probably some degree of a personal nature to the attacks. ${ }^{6}$ Also, a culture of silence has been shown to encourage further bullying. ${ }^{7}$

We cannot expect residents to do the "hard work" of enduring abuse and then excel during their surgical training. Trainees who show decreased interest in working with an abusive surgeon are not exhibiting passive-aggressive behavior but instead self-protective behavior. Residents must be encouraged and empowered to respond firmly and calmly with a simple "That's inappropriate, sir or ma'am." A simple yet effective response like this hopefully will stem the abusive behavior without causing significant disruption, even in the operating room. Patient care is the responsibility of the entire team. An attending surgeon who engages in such behavior is not acting as an effective leader to trainees. As attending surgeons, we want to teach our trainees to operate and take care of patients. However, we also want to teach them to be effective leaders who conduct themselves with honor and dignity. A technically excellent surgeon will not succeed if that surgeon fails to display professionalism repeatedly.

We agree that surgical training is improved by being other-focused. Other-focused surgeons place the collective good above their own. But doing the uncomfortable work of speaking up against abuse is an example of 
other-focused behavior. Speaking up in an effective but nonconfrontational manner will create a more positive environment for everyone and help trainees in the future.

\section{References}

1. Pasque MK. Getting the most from your cardiothoracic surgical training: it's all about behavior. J Thorac Cardiovasc Surg. 2022;164:e257-62.

2. Pei KY, Hafler J, Alseidi A, Slade MD, Klingensmith M, Cochran A. National assessment of workplace bullying among academic surgeons in the United States. JAMA. 2020;155:524-6.

3. Gostlow H, Vega C, Marlow N, Babidge W, Maddern G. Do surgeons react? A retrospective analysis of surgeons' response to harassment of a colleague during simulated operating theatre scenarios. Ann Surg. 2018; 268:277-81.

4. Hu Y, Ellis R, Hewitt D, Yang A, Cheung E, Moskowitz J, et al. Discrimination, abuse, harassment and burnout in surgical residency training. $N$ Engl J Med. 2019;381:1741-52.

5. Shanafelt T, Noseworthy J. Executive leadership and physician well-being: nine organizational strategies to promote engagement and reduce burnout. Mayo Clin Proc. 2017;92:129-46.

6. Zhang L, Ellis R, Ma M, Cheung E, Hoyt D, Bilimoria K, et al. Prevalence, types and sources of bullying reported by United States general surgery residents in 2019. JAMA. 2020;323:2093-5.

7. Pei K, Cochran A. Workplace bullying among surgeons-the perfect crime. Ann Surg. 2019;269:43-4.
See Article page e257.

\section{Commentary: Building culture: Pay it forward}

\author{
Alexander A. Brescia, MD, MSc, and \\ Gorav Ailawadi, MD, MBA
}

In an important expert opinion, Dr Pasque describes how trainee behavior is the most important factor in determining the value of one's cardiothoracic surgical training. ${ }^{1}$ Conversely, a training program's culture and treatment of residents are also linked to trainee behavior. One powerful theme from Dr Pasque's contribution is maintaining enough humility and positivity during training to endure "being stupid" to be amenable to learning and eliminating "black holes" in education that can exist during training but are expected by all those around you to be gone the day training ends. ${ }^{1}$ As Dr Pasque notes, "your reputation is only as good as your most recent performance." ${ }^{1}$ In this regard, many parallels exist between cardiothoracic training and athletics. During the recent NBA Finals, Milwaukee Bucks star Giannis Antetokounmpo had this to add:

From the Department of Cardiac Surgery, University of Michigan, Ann Arbor, Mich. Disclosures: The authors reported no conflicts of interest.

The Journal policy requires editors and reviewers to disclose conflicts of interest and to decline handling or reviewing manuscripts for which they may have a conflict of interest. The editors and reviewers of this article have no conflicts of interest.

Received for publication Aug 30, 2021; revisions received Aug 30, 2021; accepted for publication Aug 31, 2021; available ahead of print Sept 4, 2021.

Address for reprints: Alexander A. Brescia, MD, MSc, Department of Cardiac Surgery, Frankel Cardiovascular Center, University of Michigan, 1500 E Medical Center Dr, Ann Arbor, MI 48109 (E-mail: abrescia@med.umich.edu).

J Thorac Cardiovasc Surg 2022;164:e264-5

$0022-5223 / \$ 36.00$

Copyright (c) 2021 by The American Association for Thoracic Surgery

https://doi.org/10.1016/j.jtcvs.2021.08.071
Check for updates

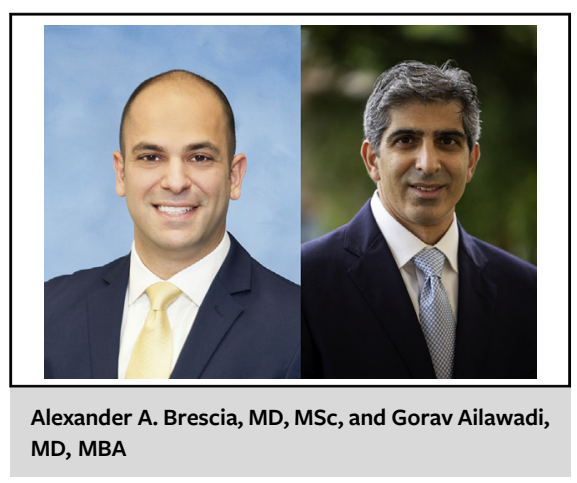

CENTRAL MESSAGE

While cardiothoracic trainees

must have the motivation to

maximize their surgical training,

faculty-led training programs

have a responsibility to foster a

culture that shapes behavior.

\begin{abstract}
"The mindset to have? When you focus on the past, that's your ego. 'I did [this] in the past. I won [that] in the past.' When I focus on the future, that's my pride. 'I'm going to dominate.' That's your pride talking. I try to focus on the moment. In the present. That's humility. That's being humble.",
\end{abstract}

These lessons about ego, pride, and humility are also relevant to cardiothoracic trainees who must constantly focus on optimizing themselves as learners and surgeons in the present.

Peer and faculty mentorship for incoming trainees are essential in the current era of cardiothoracic education. While as Dr Pasque concludes behavior is essential, 